\title{
A 17-Gene Signature Predicted Prognosis in Renal Cell Carcinoma
}

\author{
Fan Li, Weifeng Hu, Wei Zhang, Guohao Li, and Yonglian Guo \\ Department of Urology, The Central Hospital of Wuhan, Tongji Medical College, Huazhong University of Science and Technology, \\ Wuhan 430014, China
}

Correspondence should be addressed to Yonglian Guo; guoyl111@aliyun.com

Received 19 July 2019; Accepted 13 November 2019; Published 27 February 2020

Academic Editor: Marcello Ciaccio

Copyright (C) 2020 Fan Li et al. This is an open access article distributed under the Creative Commons Attribution License, which permits unrestricted use, distribution, and reproduction in any medium, provided the original work is properly cited.

Renal cell carcinoma (RCC), which was one of the most common malignant tumors in urinary system, had gradually increased incidence and mortality in recent years. Although significant advances had been made in molecular and biology research on the pathogenesis of RCC, effective treatments and prognostic indicators were still lacking. In order to predict the prognosis of RCC better, we identified 17 genes that were associated with the overall survival (OS) of RCC patients from The Cancer Genome Atlas (TCGA) dataset and a 17-gene signature was developed. Through SurvExpress, we analyzed the expression differences of the 17 genes and their correlation with the survival of RCC patients in five datasets (ZHAO, TCGA, KIPAN, KIRC, and KIRP), and then evaluated the survival prognostic significance of the 17-gene signature for RCC. Our results showed that the 17-gene signature had a predictive prognostic value not only in single pathologic RCC, but also in multiple pathologic types of RCC. In conclusion, the 17-gene signature model was related to the survival of RCC patients and could help predict the prognosis with significant clinical implications.

\section{Introduction}

Renal cell carcinoma (RCC), the main form of kidney cancer, was the second most common cancer in the urological system and accounted for approximately $3 \%$ of malignant neoplasms worldwide [1]. It included a variety of malignant tumors that originated from renal tubular epithelial cells and up to $85 \%$ of kidney cancer belonged to RCC [2]. The incidence and mortality had gradually increased in recent years [3]. RCC was usually sporadic (about 96\%), but occasionally familial (about 4\%), and it was often associated with specific gene mutations [4]. It occurred more frequently in men than in women (ratio of $1.7: 1$ ), and most people were older, with an average age of 64 years $[5,6]$. Clear cell renal cell carcinoma (ccRCC) accounted for $80-90 \%$ of RCC [7, 8 ] and was the predominant histological subtype characterized by its resistance to conventional chemotherapy and radiotherapy [9].

Although surgical tumor resection was an effective treatment for RCC at present [10-12], radical surgery cannot completely cure RCC [13, 14]. Recent studies had focused on the possibility of combining strategy for improv- ing the therapeutic value of existing standard therapies, including chemotherapy and radiotherapy [15, 16]; however, RCC was not sensitive to radiotherapy and chemotherapy $[17,18]$. Patients in early stage of RCC $(>50 \%$ of cases) had a favorable prognosis after nephrectomy, with the 5-year survival rate of about $81 \%$. However, $10-30 \%$ of patients with early RCC would undergo tumor recurrence after nephrectomy [19], and about $20 \%$ of patients had presented metastatic diseases when they came for treatment [20]. The common metastatic sites of RCC included the brain, lung, and bones. In patients with metastatic diseases, the median survival time ranged from 6 to 12 months [21]. For advanced stage of RCC, systemic therapy was the foundational treatment. On account of the extremely high rate of local invasion and metastasis, as well as the resistance to chemotherapy and radiotherapy, over 30\% of RCC patients with metastasis had a 5-year survival rate below $20 \%[22,23]$, which indicated a poor long-term prognosis. Therefore, it was essential to research on the development mechanism of RCC at molecular level. This may help determine the invasion and metastasis ability of RCC and its malignancy, predict the prognosis of RCC, develop a 


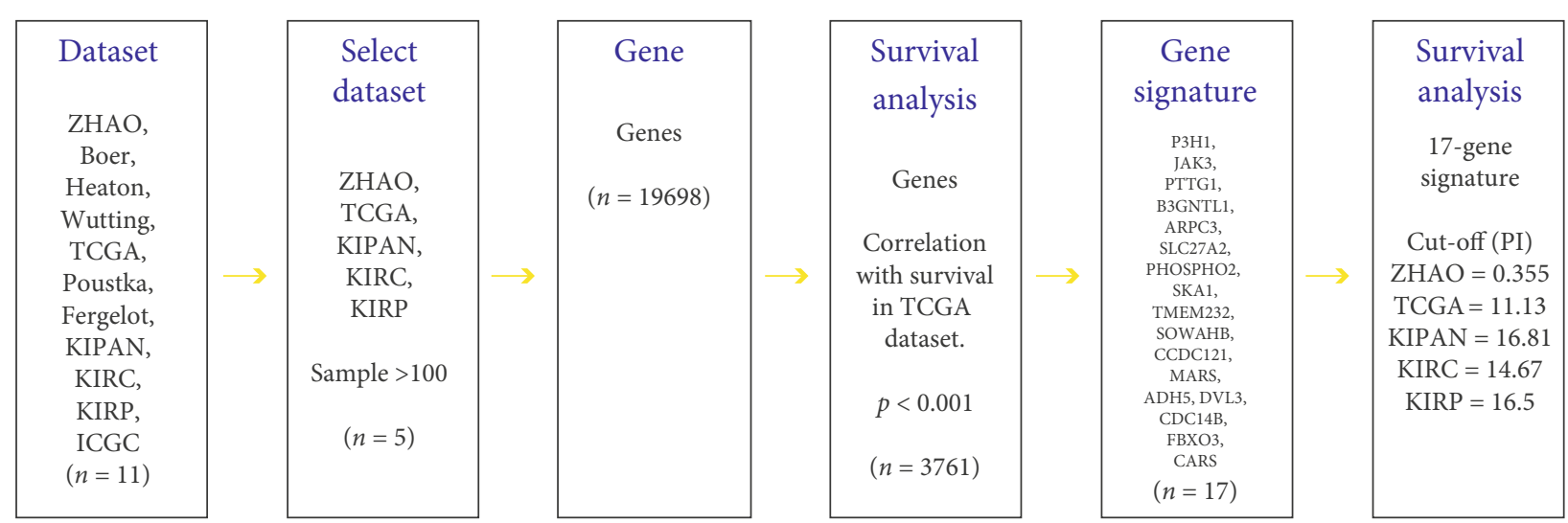

FIGURE 1: The procedure flow chart of SurvExpress. Schematic overview of the procedure used in our study to construct the 17-gene signature.

reasonable treatment program, and provide new ideas for molecular targeted therapy.

In order to solve this unmet need, a prognostic 17-gene signature model was developed. We hypothesized that this 17-gene signature may reflect the risk level of adverse clinical outcomes in RCC, which may be useful to correctly predict the overall survival (OS) of RCC and aid the clinicians in treatment planning.

\section{Materials and Methods}

2.1. Selection and Analysis of Databases. All the data were analyzed using SurvExpress (http://bioinformatica.mty .itesm.mx:8080/Biomatec/SurvivaX.jsp). SurvExpress was a comprehensive gene expression analysis tool that was based on a number of databases. It can provide risk assessment and survival analysis in many cancer datasets [24, 25]. In this analysis, SurvExpress was used to provide Kaplan-Meier log rank analysis, risk evaluation, etc. For RCC, SurvExpress incorporated 11 independent public databases. In our study, we only included databases with a sample number greater than 100, and five databases (ZHAO, TCGA, KIPAN, KIRC and KIRP) were screened out, containing a total of 19698 coding genes. Then, 3761 genes associated with the prognosis of RCC were selected out in the TCGA database from the 19698 genes $(p<0.001)$. After that, the 3761 genes were sorted by $p$ value and the top 99 genes were combined. In this combination, genes with a significant difference in expression levels were picked out to form a 17-gene signature (Figure 1). Their gene ID, full name, and function were shown in Table 1.

2.2. Study Design. Using SurvExpress, we analyzed the expression differences of the 17 genes and their correlation with the survival of RCC patients in the five datasets (ZHAO, TCGA, KIPAN, KIRC and KIRP), and then evaluated the survival prognostic significance of the 17-gene signature for RCC (Table 1). The prognostic index (PI), which was also known as the risk score, was often used to perform risk assessment and generate risk groups. The PI was the linear component of the Cox model, PI $=\mathrm{b} 1 \times 1+\mathrm{b} 2 \mathrm{x} 2+\cdots+\mathrm{bixi}$, where the bi can be obtained from the Cox fitting and $x i$ was the expression value. Each bi can be construed as a risk parameter [26]. According to the PI formula, each patient had a corresponding PI. Sort PI from low to high and select the optimal cut-off value. Then, the patients were divided into high-risk and low-risk groups according to the optimal cut-off value (Figure 2).

2.3. Statistical Analysis. To evaluate the prognostic value of the 17-gene signature, Kaplan-Meier estimator was used to plot survival curves and the log-rank test was performed to compare the differences between the two groups $[26,27]$. Kaplan-Meier can also be used to provide the receiver operating characteristic (ROC) curve to determine the accuracy of the 17-gene signature in predicting the prognosis of RCC. The ROC analysis was a tool used to describe the discrimination accuracy of a diagnostic test or prediction model [28]. One of the most commonly used ROC summary indices was the area under the ROC curve (AUC). The AUC values were calculated from the ROC curve $[28,29] . p<0.05$ was considered to be statistically significant.

\section{Results}

3.1. Survival Analysis of the 17 Genes in TCGA Dataset. We analyzed the expression differences of the 17 genes in TCGA dataset with SurvExpress. The gene ID, full name, and function were obtained from the NCBI FTP site and GeneCards. Our analysis showed that the 17 genes all had significant prognostic differences in the TCGA database $(p<0.001)$ (Table 1).

3.2. Sort PI from Low to High and Select the Optimal Cut-off Value. Sort PI from low to high and select the optimal cutoff value. The optimal cut-off values of PI in the five databases (TCGA, KIRC, KIRP, KIPAN, and ZHAO) were $11.13,14.67,16.5,16.81$, and 0.355 (Figure 1). Then, the patients were divided into high-risk and low-risk groups according to the optimal cut-off value (Figure 2).

3.3. The 17-Gene Signature Showed a Predictive Prognostic Significance in RCC. Survival differences between predicted 
TABLE 1: The expression differences of the 17 genes in TCGA dataset with SurvExpress.

\begin{tabular}{|c|c|c|c|c|c|}
\hline Gene & $\begin{array}{l}\text { Gene } \\
\text { ID }\end{array}$ & Full name & Function & HR (95\% CI) & $p$ value \\
\hline P3H1 & 64175 & Prolyl 3-hydroxylase 1 & $\begin{array}{l}\text { Has prolyl 3-hydroxylase activity and growth } \\
\text { suppressive activity in fibroblasts and involve in the } \\
\text { secretory pathway of cells }\end{array}$ & $2.96(2.09-4.18)$ & $9.25 E-10$ \\
\hline JAK3 & 3718 & Janus kinase 3 & $\begin{array}{l}\text { Nonreceptor tyrosine kinase involved in various } \\
\text { processes such as cell growth, development, or } \\
\text { differentiation. Mediate essential signaling in both } \\
\text { innate and adaptive immunity and hematopoiesis } \\
\text { during T cell development. }\end{array}$ & $3.04(2.13-4.33)$ & $8.521 E-10$ \\
\hline PTTG1 & 9232 & $\begin{array}{c}\text { Pituitary tumor-transforming } \\
1\end{array}$ & $\begin{array}{c}\text { Regulatory protein which plays a central role in } \\
\text { chromosome stability, the p53/TP53 pathway, and } \\
\text { DNA repair }\end{array}$ & $3.07(2.15-4.4)$ & $7.852 E-10$ \\
\hline B3GNTL1 & 146712 & $\begin{array}{c}\text { BetaGal beta-1,3-N- } \\
\text { acetylglucosaminyltransferase } \\
\text { like } 1\end{array}$ & Putative glycosyltransferase. & $3.02(2.12-4.29)$ & $7.533 E-10$ \\
\hline ARPC3 & 10094 & $\begin{array}{l}\text { Actin-related protein } 2 / 3 \\
\text { complex subunit } 3\end{array}$ & $\begin{array}{c}\text { Localize to the lamellipodia of stationary and locomote } \\
\text { fibroblasts, inducing actin polymerization and potentially } \\
\text { participating in lamellipodial protrusion }\end{array}$ & $3.08(2.15-4.41)$ & $7 E-10$ \\
\hline SLC27A2 & 26458 & $\begin{array}{l}\text { Solute carrier family } 27 \text { (fatty } \\
\text { acid transporter), member } 2\end{array}$ & $\begin{array}{l}\text { Acyl-CoA synthetase probably involves in bile acid } \\
\text { metabolism. May have additional roles in fatty acid } \\
\text { metabolism and be involved in translocation of } \\
\text { long-chain fatty acids across membranes }\end{array}$ & $3.01(2.12-4.28)$ & $6.999 E-10$ \\
\hline PHOSPHO2 & 73373 & Phosphatase, orphan 2 & $\begin{array}{l}\text { High activity toward pyridoxal } 5^{\prime} \text {-phosphate. Also } \\
\text { active at a much lower level toward } \\
\text { phosphoethanolamine, pyrophosphate, } \\
\text { phosphocholine, phospho-l-tyrosine, } \\
\text { fructose-6-phosphate, p-nitrophenyl phosphate, } \\
\text { and h-glycerophosphate. }\end{array}$ & $3.01(2.12-4.27)$ & $6.661 E-10$ \\
\hline SKA1 & 220134 & $\begin{array}{l}\text { Spindle- and kinetochore- } \\
\text { associated complex subunit } 1\end{array}$ & $\begin{array}{l}\text { Component of the SKA1 complex that is essential for } \\
\text { proper chromosome segregation. High expression levels } \\
\text { of SKA1 were significantly associated with low DFS. }\end{array}$ & $3.09(2.16-4.41)$ & $5.455 E-10$ \\
\hline TMEM232 & 642987 & Transmembrane protein 232 & Unclear. & $3.00(2.12-4.23)$ & $4.299 E-10$ \\
\hline SOWAHB & 345079 & $\begin{array}{l}\text { Sosondowah ankyrin repeat } \\
\text { domain family member B }\end{array}$ & Unclear. & $3.10(2.17-4.42)$ & $4.173 E-10$ \\
\hline CCDC121 & 403180 & $\begin{array}{l}\text { Coiled-coil domain- } \\
\text { containing } 121\end{array}$ & Unclear. & $3.14(2-4.47)$ & $2.512 E-10$ \\
\hline MARS & 4141 & Methionyl-tRNA synthetase & $\begin{array}{l}\text { A protein-coding gene plays a role in the synthesis of } \\
\text { ribosomal RNA in the nucleolus. }\end{array}$ & $3.09(2.18-4.37)$ & $1.969 E-10$ \\
\hline ADH5 & 128 & $\begin{array}{l}\text { Alcohol dehydrogenase } 5 \\
\text { (class III), chi polypeptide }\end{array}$ & $\begin{array}{l}\text { Catalyze the oxidation of long-chain primary alcohols } \\
\text { and the oxidation of S-(hydroxymethyl) glutathione. } \\
\text { Also oxidize long-chain omega-hydroxy fatty acids. }\end{array}$ & $3.19(2.24-4.56)$ & $1.649 E-10$ \\
\hline DVL3 & 1857 & $\begin{array}{l}\text { Dishevelled segment polarity } \\
\text { protein } 3\end{array}$ & $\begin{array}{c}\text { Involve in the signal transduction pathway mediated by } \\
\text { multiple Wnt genes. }\end{array}$ & $3.17(2.23-4.49)$ & $9.754 E-11$ \\
\hline $\mathrm{CDC} 14 \mathrm{~B}$ & 8555 & Cell division cycle $14 \mathrm{~B}$ & $\begin{array}{l}\text { Dual-specificity phosphatase involved in DNA damage } \\
\text { response. Essential regulator of the G2 DNA damage } \\
\text { checkpoint, a key activator of the anaphase-promoting } \\
\text { complex/cyclosome (APC/C). }\end{array}$ & $3.32(2.32-4.74)$ & $5.069 E-11$ \\
\hline FBXO3 & 26273 & F-box protein 3 & $\begin{array}{l}\text { Substrate recognition component of the SCF } \\
\text { (SKP1-CUL1-F-box protein)-type E3 ubiquitin ligase } \\
\text { complex. Mediate the ubiquitination of HIPK2 and } \\
\text { probably that of EP300, leading to rapid degradation by } \\
\text { the proteasome. }\end{array}$ & $3.32(2.32-4.74)$ & $4.352 E-11$ \\
\hline CARS & 833 & Cysteinyl-tRNA synthetase & $\begin{array}{c}\text { An important tumor-suppressor gene. Alterations in } \\
\text { this region is associated with Beckwith-Wiedemann } \\
\text { syndrome; Wilms tumor; adrenocortical carcinoma; } \\
\text { and lung, ovarian, and breast cancers, } \\
\text { rhabdomyosarcoma. }\end{array}$ & $3.69(2.56-5.33)$ & $2.533 E-12$ \\
\hline
\end{tabular}




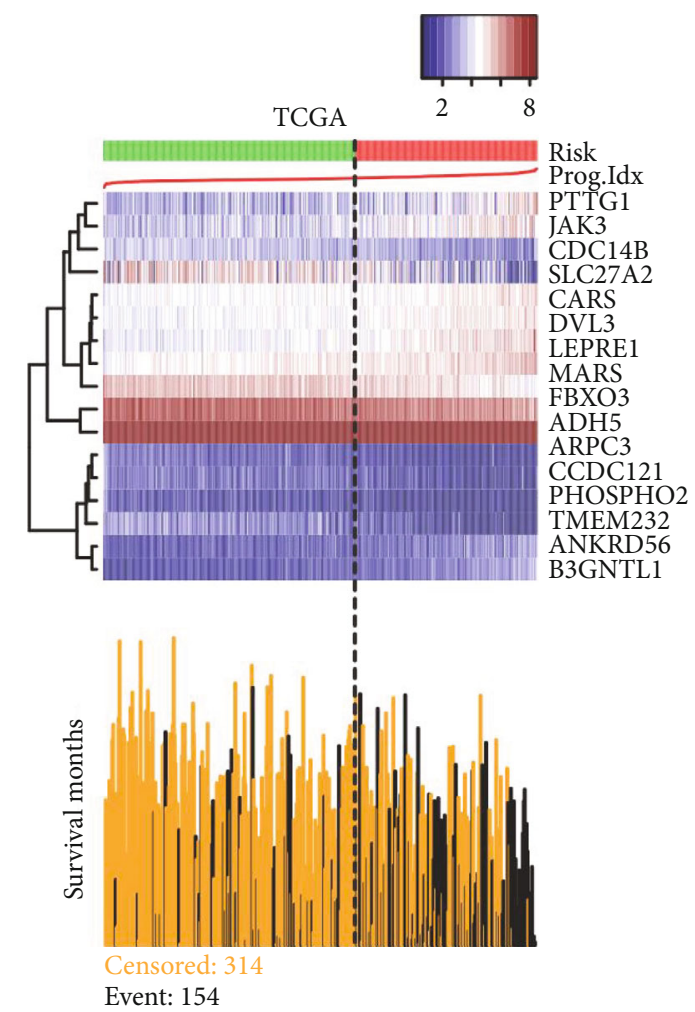

(a)

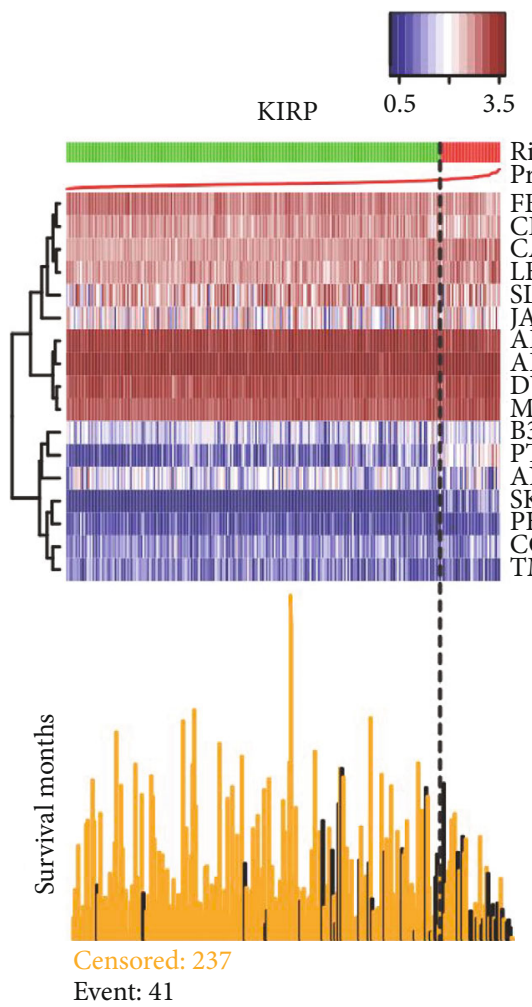

(c)

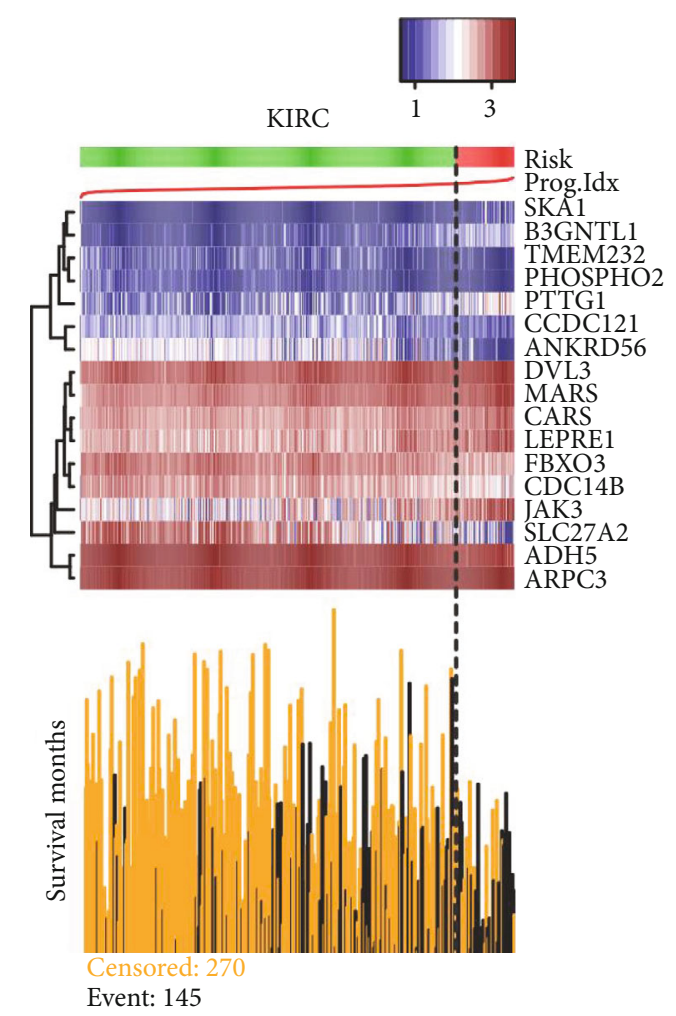

(b)

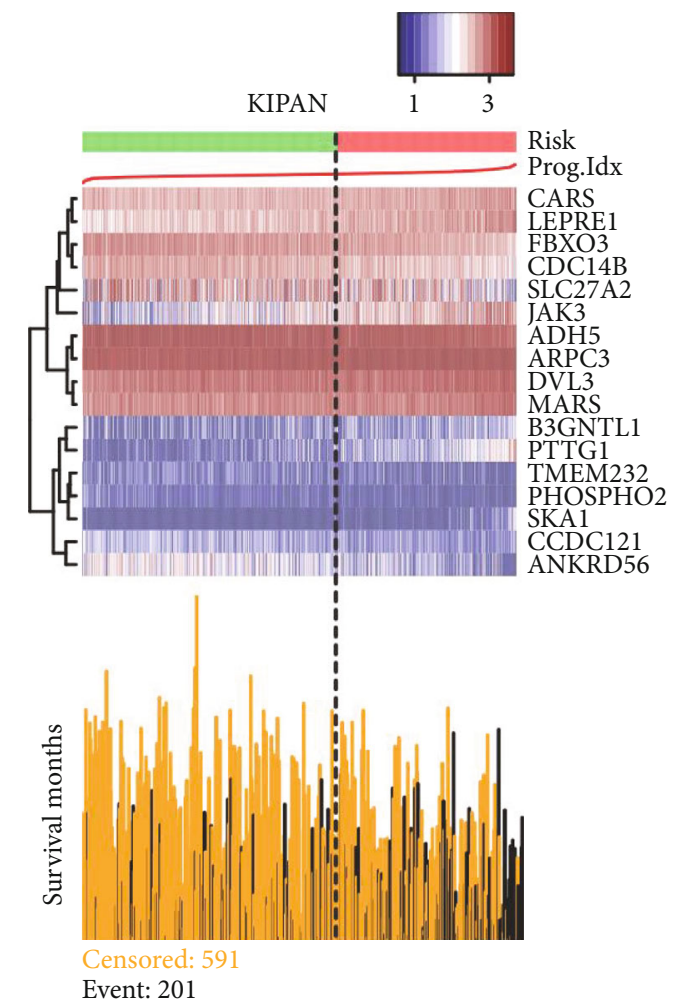

(d)

Figure 2: Continued. 


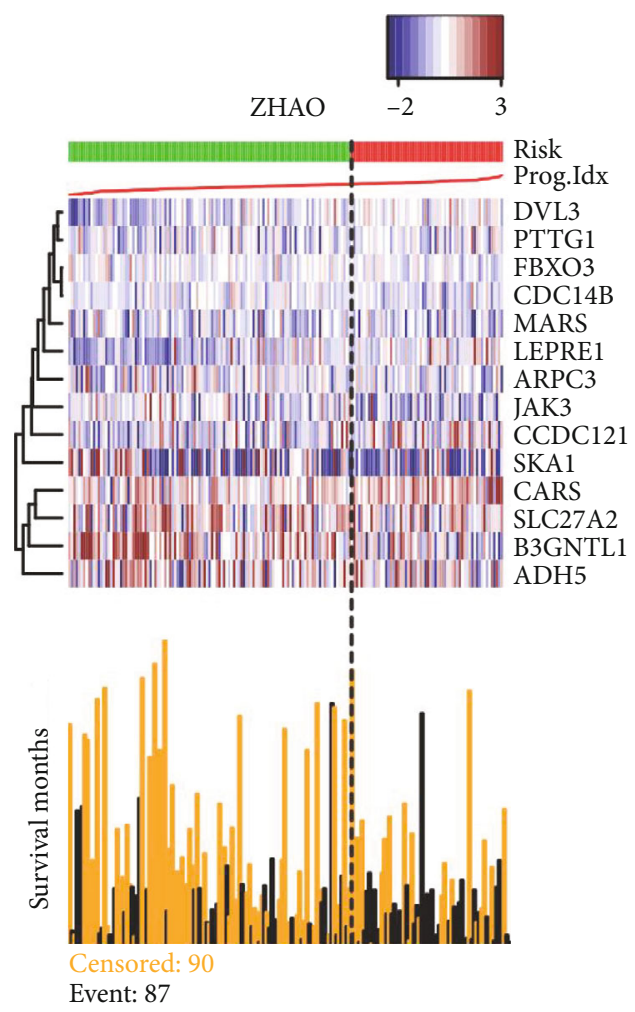

(e)
Cut-off (Prog.Idx)
TCGA $=11.13$
KIPAN $=16.81$
KIRC $=14.67$
KIRP $=16.5$
ZHAO $=0.355$

(f)

Figure 2: Sort PI from low to high and select the optimal cut-off value. Then, the patients were divided into high-risk and low-risk groups according to the optimal cut-off value. Red represented high-risk group and green represented low-risk group. Each figure was composed of the upper gene expression heat map and the nether prognostic index graph. (a) TCGA database contained 468 patients ( $n=154$ in the high-risk group, $n=314$ in the low-risk group) and the optimal cut-off value of PI was 11.13. (b) KIRC database contained 415 patients ( $n=145$ in the high-risk group, $n=270$ in the low-risk group) and the optimal cut-off value of PI was 14.67. (c) KIRP database contained 278 patients ( $n=41$ in the high-risk group, $n=237$ in the low-risk group) and the optimal cut-off value of PI was 16.5. (d) KIPAN database contained 792 patients $(n=201$ in the high-risk group, $n=591$ in the low-risk group) and the optimal cut-off value of PI was 16.81. (e) ZHAO database contained 177 patients ( $n=87$ in the high-risk group, $n=90$ in the low-risk group) and the optimal cut-off value of PI was 0.355. (f) The optimal cut-off value of the five databases (TCGA: 11.13; KIPAN: 16.81; KIRC: 14.67; KIRP: 16.5; ZHAO: 0.355).

low-risk and high-risk groups were evaluated with KaplanMeier survival curves (Figure 3). TCGA data showed that the prognosis of patients with low risk $(n=272)$ was significantly better than high-risk group patients $(n=196)$ $(\mathrm{HR}(95 \% \mathrm{CI})=4.05$ (2.85-5.74), $p<0.001)$ (Figure 3(a)). KIRC database was a corresponding database for kidney renal clear cell carcinoma, which also showed a prognostic value of the 17-gene signature $(p<0.001)$ (Figure 3(b)). The research object of KIRP database was kidney renal papillary cell carcinoma. Likewise, our analysis found a significant prognostic difference between the two groups $(n=240$ in the low-risk group and $n=38$ in the high-risk group) $(\mathrm{HR}(95 \% \mathrm{CI})=9.58$ (4.97-18.45), $p<0.001)$ (Figure 3(c)). KIPAN incorporated three types of kidney cancer, including kidney chromophobe, kidney renal clear cell carcinoma, and kidney renal papillary cell carcinoma. For the comprehensive KIPAN database, our 17-gene signature had a significant predictive significance as well $(p<0.001)$ (Figure $3(d)$ ). ZHAO database (GSE3538) revealed a significant prognostic difference between the low-risk group $(n=115)$ and the high-risk group $(n=62) \quad(\mathrm{HR}(95 \% \mathrm{CI})=2.27 \quad(1.49$ $3.47), p<0.001)$, indicating that the 17 -gene signature can also be used as a prognostic indicator in the ZHAO database (Figure 3(e)). In conclusion, our results demonstrated that the 17-gene signature had a predictive prognostic value not only in single pathologic RCC but also in multiple pathologic types of RCC.

3.4. The Accuracy Analysis of the 17-Gene Signature in Predicting the Prognosis of RCC. In order to determine the accuracy of the 17-gene signature in predicting the prognosis of RCC, we conducted the true positives and false positives analysis by SurvExpress (Figure 4). The receiver operating characteristic curve (ROC) for predicting 5-year survival was obtained according to PI. The time points provided in Figures 4(a) and 4(b) were months, while the time points in Figures 4(c)-4(e) were days. Our analysis revealed that in different time points, different pathological types of RCC, and different databases, the ROC curves all had an area under the ROC curve (AUC) of greater than 0.6 (TCGA: 0.833, KIRC: 0.813, KIRP: 0.812, KIPAN: 0.778, and ZHAO: 0.697 ), suggesting that the 17 -gene signature had certain accuracy in predicting RCC prognosis. 
TCGA

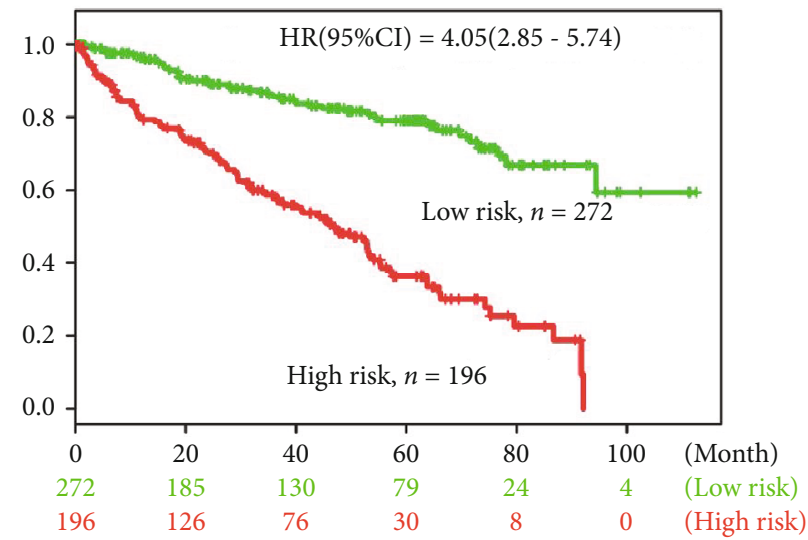

(a)

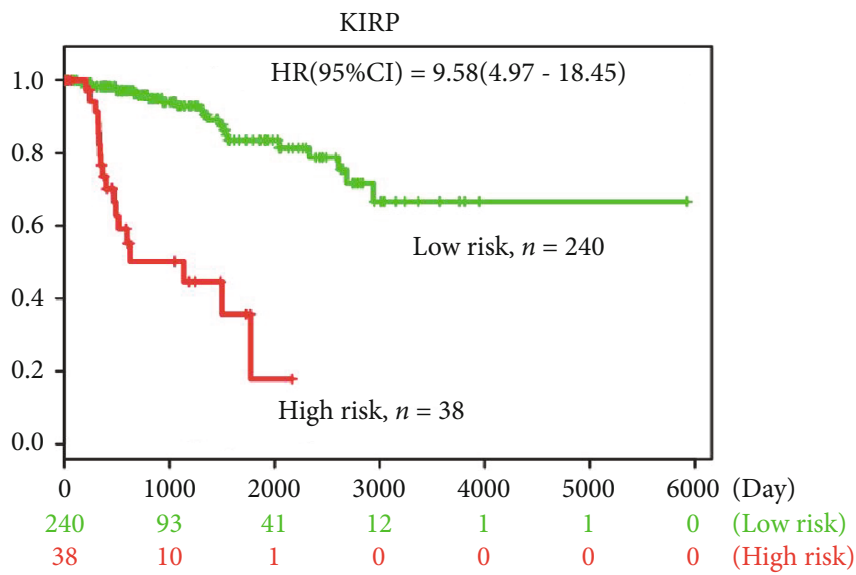

(c)

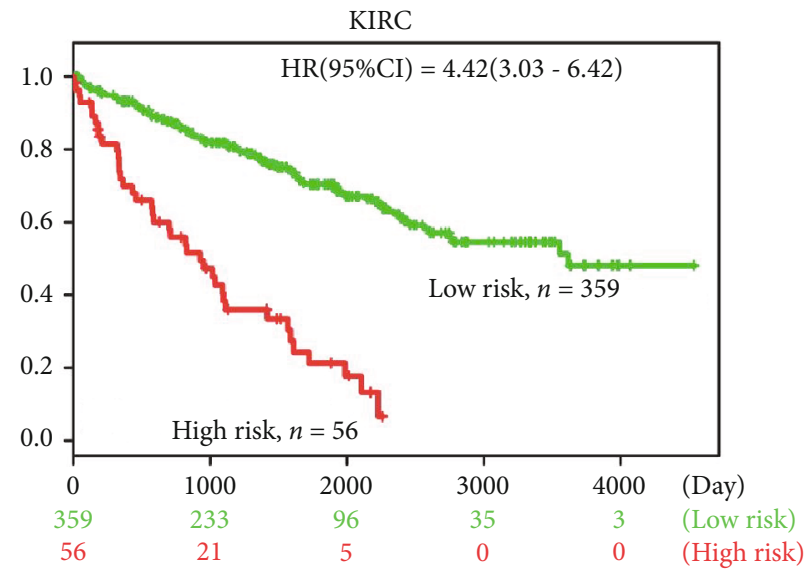

(b)

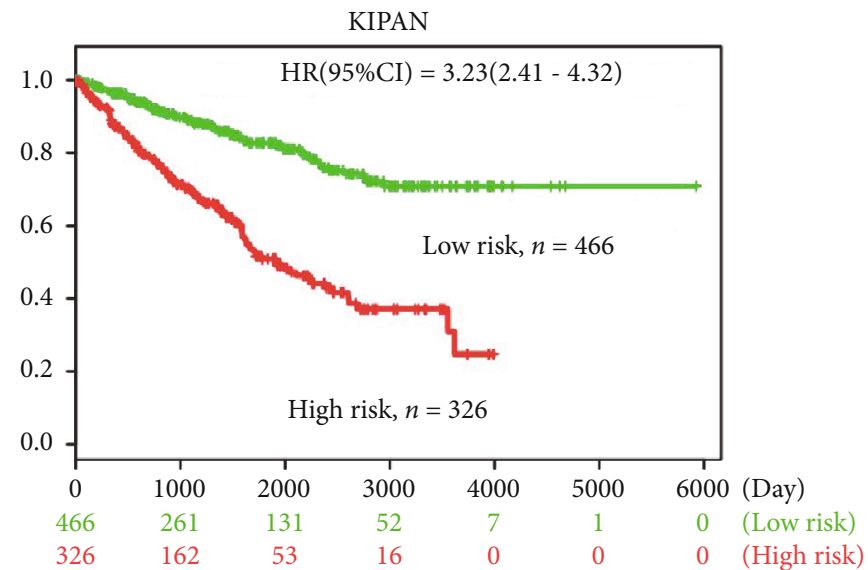

(d)

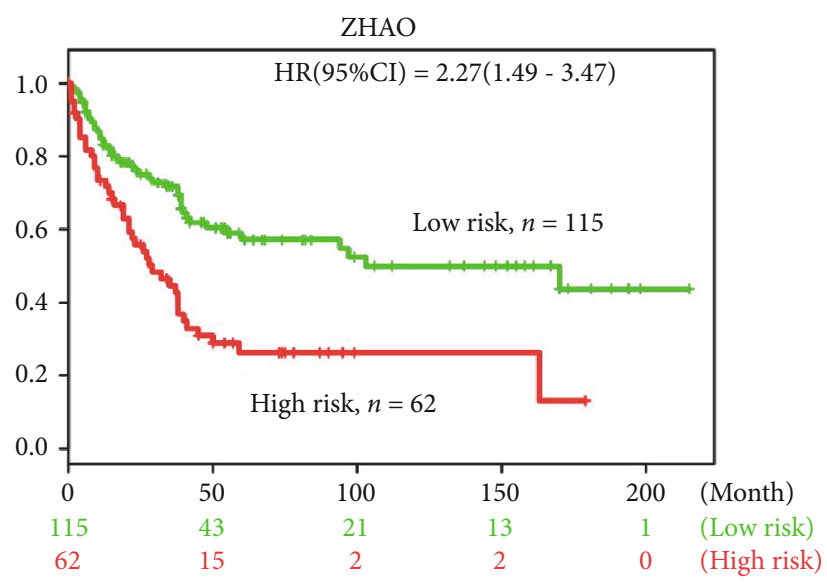

(e)

FiguRE 3: Survival differences between the predicted low-risk and high-risk groups were evaluated through Kaplan-Meier survival curves. The results indicated that the prognosis of patients with low risk was all significantly better than that in the high-risk group in the TCGA (a), KIRC (b), KIRP (c), KIPAN (d), and ZHAO (e) databases $(p<0.001)$.

\section{Discussion}

RCC was the third most common malignancy in the urogenital system, which represented about $2 \%$ to $3 \%$ of cancers in adults [30]. The genesis and progression of RCC involved various factors, including carcinogenic substances and environmental factors $[31,32]$. Smoking and obesity were consid- ered to be risk factors for the development of RCC [33]. RCC was divided into four histological main subtypes [34]. In general, WHO distinguished RCC into clear cell RCC (ccRCC) and nonccRCC. Thereinto, ccRCC was the predominant subtype of RCC [35].

RCC was classified as an "immunogenic" tumor based on the following characteristics: spontaneous regression of the 


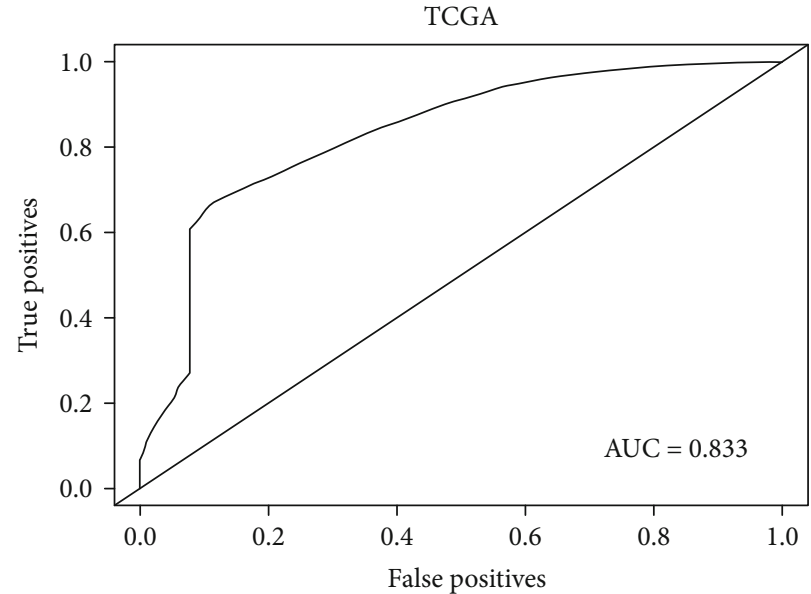

(a)

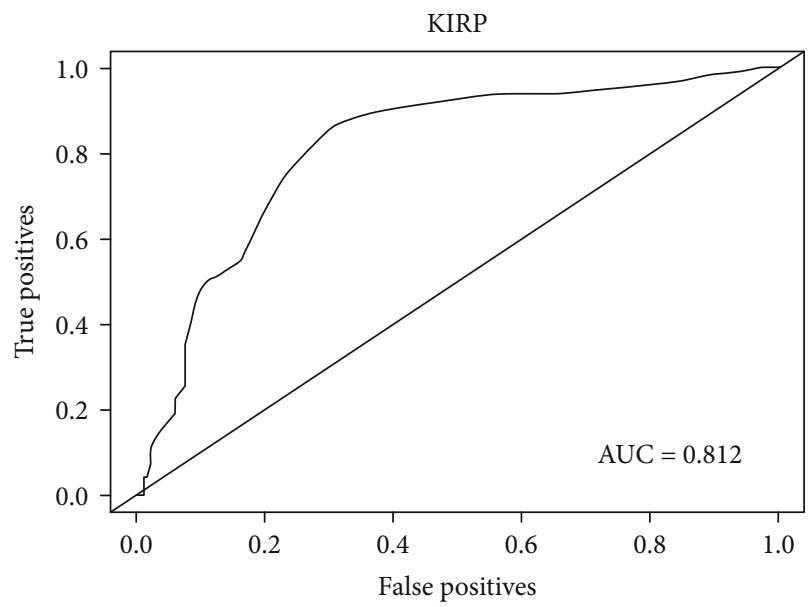

(c)

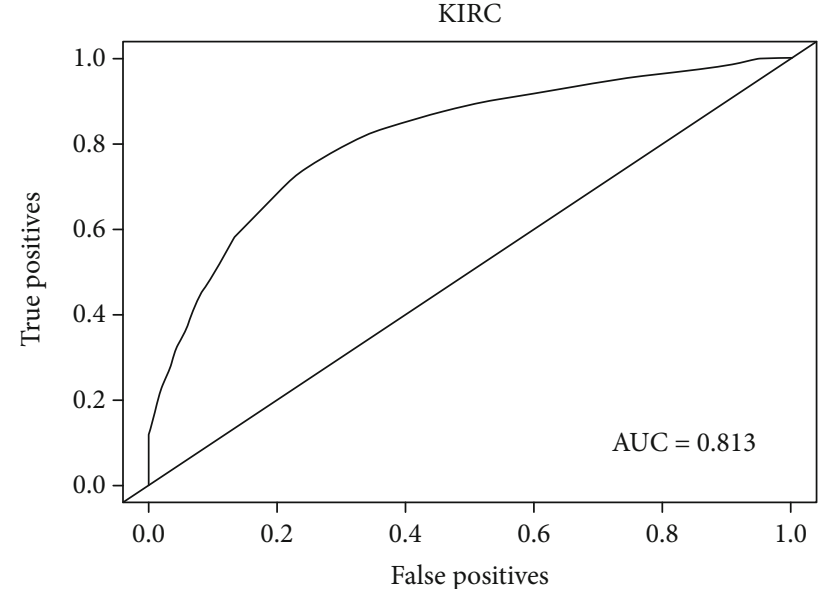

(b)

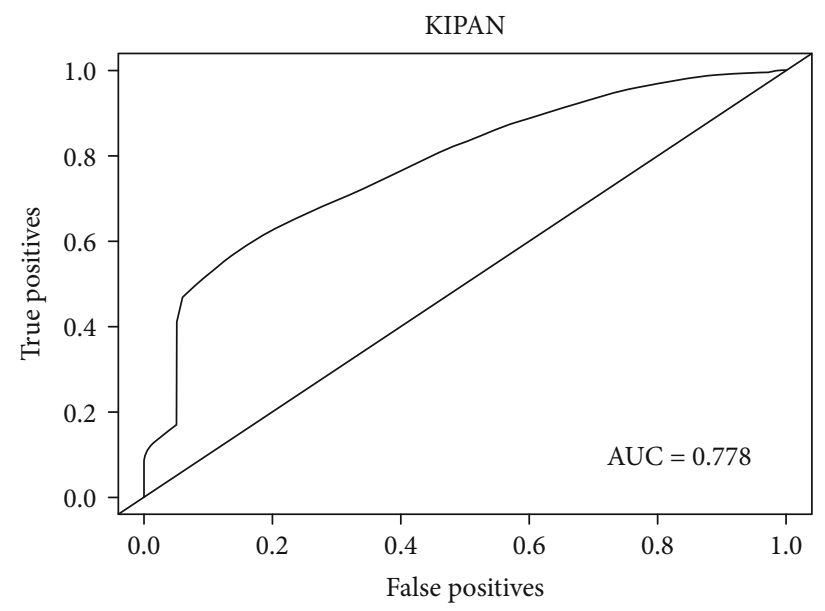

(d)

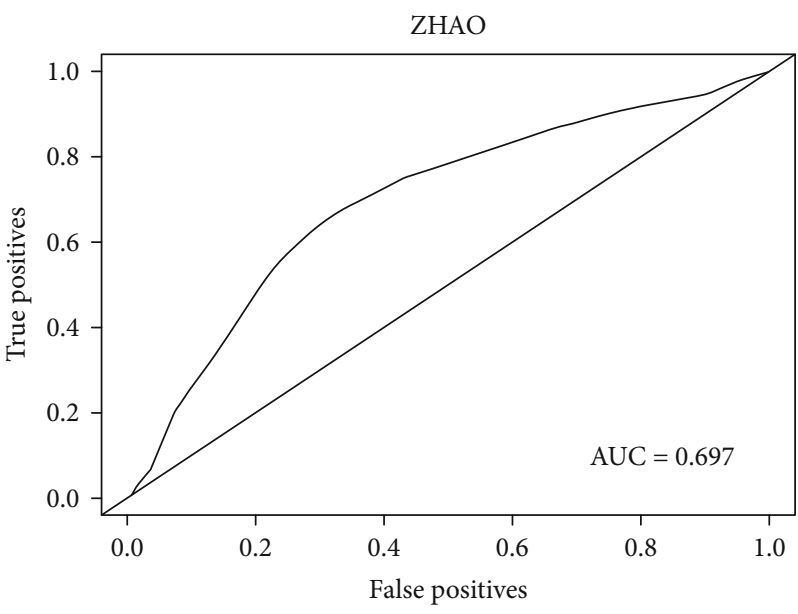

(e)

FIGURE 4: The accuracy analysis of the 17-gene signature in predicting the prognosis of RCC. Kaplan-Meier was used to obtain ROC curves. The results showed that the ROC curves all had an area under the ROC curve (AUC) of greater than 0.6 in the five databases (TCGA, KIRC, KIRP, KIPAN, and ZHAO) $(p<0.001)$.

tumor, high levels of $\mathrm{T}$ cell infiltration in the tumor, and reactivity to immunotherapy such as interleukin-2 (IL-2) and interferon alpha (IFN- $\alpha$ ) [36]. However, due to low efficacy and high adverse reactions, these therapeutic measures were not ideal. $30 \%$ of patients had already presented advanced disease or other metastatic diseases when they came for treatment [37]. Eventually, about $40 \%$ of patients died of metastases [38]. Therefore, it was urgently needed to find potential 
prognostic biomarkers to predict the prognosis of RCC and draw up rational treatment programs.

In the present study, we first identified 17 genes associated with OS of RCC patients from the TCGA dataset. Through SurvExpress, we analyzed the expression differences of the 17 genes in RCC patients in the TCGA dataset. Our analysis showed that the 17 genes had significant prognostic differences in the TCGA database $(p<0.001)$. Then, a $17-$ gene signature model was developed and its correlation with the survival of RCC patients in the five datasets was analyzed, respectively. The patients were divided into low-risk and high-risk groups according to the optimal cut-off value. Survival differences between the predicted low-risk and high-risk groups were evaluated with Kaplan-Meier survival curves. The results presented that the prognosis of patients with low risk was all significantly better than that of highrisk group patients in the five databases $(p<0.001)$, suggesting that the 17-gene signature had a predictive prognostic value not only in single pathologic RCC but also in multiple pathologic types of RCC.

Finally, in order to determine the accuracy of the 17-gene signature in predicting the prognosis of RCC, the receiver operating characteristic curve (ROC) for predicting 5-year survival was obtained according to PI. The value of AUC was the size of the area under the ROC curve. Typically, the AUC value was between 0.5 and 1.0, and larger AUC represented better performance [30, 31]. Our analysis revealed that the ROC curves all had an AUC of greater than 0.6 in the five databases $(p<0.001)$, suggesting that the 17-gene signature had certain accuracy in predicting the prognosis of RCC.

\section{Conclusions}

In summary, our study demonstrated a survival prognostic significance of a 17-gene signature for RCC. This may be a potential prognostic tool to improve the adverse clinical outcomes of RCC patients currently. Further prospective studies were needed to determine whether the 17 -gene signature can be used clinically to benefit RCC patients.

\section{Data Availability}

The data used to support the findings of this study are included within the article.

\section{Conflicts of Interest}

The authors declare that there is no conflict of interest regarding the publication of this paper.

\section{Acknowledgments}

The research was supported by a grant from the National Natural Science Foundation of China (No. 81200103).

\section{References}

[1] B. I. Rini, S. C. Campbell, and B. Escudier, "Renal cell carcinoma," The Lancet, vol. 373, no. 9669, pp. 1119-1132, 2009.
[2] P. C. Barata and B. I. Rini, "Treatment of renal cell carcinoma: current status and future directions," CA: a Cancer Journal for Clinicians, vol. 67, no. 6, pp. 507-524, 2017.

[3] N. G. Zaorsky, E. J. Lehrer, G. Kothari, A. V. Louie, and S. Siva, "Stereotactic ablative radiation therapy for oligometastatic renal cell carcinoma (SABR ORCA): a meta-analysis of 28 studies," European Urology Oncology, vol. 2, no. 5, pp. 515523, 2019.

[4] C. P. Pavlovich and L. S. Schmidt, "Searching for the hereditary causes of renal-cell carcinoma," Nature Reviews Cancer, vol. 4, no. 5, pp. 381-393, 2004.

[5] R. L. Siegel, K. D. Miller, and A. Jemal, "Cancer statistics, 2017," CA: a Cancer Journal for Clinicians, vol. 67, no. 1, pp. 7-30, 2017.

[6] T. K. Choueiri and R. J. Motzer, "Systemic therapy for metastatic renal-cell carcinoma," The New England Journal of Medicine, vol. 376, no. 4, pp. 354-366, 2017.

[7] X. Tan, Y. Liu, J. Hou, and G. Cao, "Targeted therapies for renal cell carcinoma in\&nbsp; Chinese patients: focus on everolimus," OncoTargets and Therapy, vol. 8, pp. 313-321, 2015.

[8] B. Ljungberg, K. Bensalah, S. Canfield et al., "EAU guidelines on renal cell carcinoma: 2014 update," European Urology, vol. 67, no. 5, pp. 913-924, 2015.

[9] A. Jemal, R. Siegel, E. Ward, T. Murray, J. Xu, and M. J. Thun, "Cancer statistics, 2007," CA: a Cancer Journal for Clinicians, vol. 57, no. 1, pp. 43-66, 2007.

[10] C. Cavaliere, C. D'Anielloand, C. D. Pepa, S. Pisconti, M. Berretta, and G. Facchini, "Current and emerging treatments for metastatic renal cell carcinoma," Current Cancer Drug Targets, vol. 18, no. 5, pp. 468-479, 2018.

[11] D. Miao, C. A. Margolis, W. Gao et al., "Genomic correlates of response to immune checkpoint therapies in clear cell renal cell carcinoma," Science, vol. 359, no. 6377, pp. 801-806, 2018.

[12] W. Zhai, J. Ma, R. Zhu et al., "MiR-532-5p suppresses renal cancer cell proliferation by disrupting the ETS1-mediated positive feedback loop with the KRAS-NAP1L1/P-ERK axis," British Journal of Cancer, vol. 119, no. 5, pp. 591-604, 2018.

[13] K. G. Liu, S. Gupta, and S. Goel, "Immunotherapy: incorporation in the evolving paradigm of renal cancer management and future prospects," Oncotarget, vol. 8, no. 10, pp. 17313-17327, 2017.

[14] Y. Du, S. Pahernik, B. Hadaschik et al., "Survival and prognostic factors of patients with renal cell cancer with bone metastasis in the era of targeted therapy: a single-institution analysis," Urologic Oncology: Seminars and Original Investigations, vol. 34, no. 10, pp. 431-433, 2016.

[15] J. Miao, L. Wang, M. Zhu et al., "Long-term survival and late toxicities of elderly nasopharyngeal carcinoma (NPC) patients treated by high-total- and fractionated-dose simultaneous modulated accelerated radiotherapy with or without chemotherapy," Oral Oncology, vol. 89, pp. 40-47, 2019.

[16] R. Zheng, S. Lian, X. Huang et al., "The survival benefit of intensified full-dose XELOX chemotherapy concomitant to radiotherapy and then resting-period consolidation chemotherapy in locally advanced rectal cancer," Journal of Cancer, vol. 10, no. 3, pp. 730-736, 2019.

[17] J. Xie, W. Lin, L. Huang et al., "Bufalin suppresses the proliferation and metastasis of renal cell carcinoma by inhibiting the PI3K/Akt/mTOR signaling pathway," Oncology Letters, vol. 16 , no. 3 , pp. 3867-3873, 2018. 
[18] T. Chandrasekar, Z. Klaassen, H. Goldberg, G. S. Kulkarni, R. J. Hamilton, and N. E. Fleshner, "Metastatic renal cell carcinoma: patterns and predictors of metastases-a contemporary population-based series," Urologic Oncology: Seminars and Original Investigations, vol. 35, no. 11, pp. 661.e7-661.e14, 2017.

[19] L. Cindolo, J. J. Patard, P. Chiodini et al., "Comparison of predictive accuracy of four prognostic models for nonmetastatic renal cell carcinoma after nephrectomy: a multicenter European study," Cancer, vol. 104, no. 7, pp. 1362-1371, 2005.

[20] S. Dabestani, A. Thorstenson, P. Lindblad, U. Harmenberg, B. Ljungberg, and S. Lundstam, "Renal cell carcinoma recurrences and metastases in primary non-metastatic patients: a population-based study," World Journal of Urology, vol. 34, no. 8, pp. 1081-1086, 2016.

[21] U. Capitanio, K. Bensalah, A. Bex et al., "Epidemiology of renal cell carcinoma," European Urology, vol. 75, no. 1, pp. 74-84, 2019.

[22] A. Soultati, M. Stares, C. Swanton, J. Larkin, and S. Turajlic, "How should clinicians address intratumour heterogeneity in clear cell renal cell carcinoma?," Current Opinion in Urology, vol. 25, no. 5, pp. 358-366, 2015.

[23] X. Feng, N. Yan, W. Sun et al., "miR-4521-FAM129A axial regulation on ccRCC progression through TIMP-1/MMP2/MMP9 and MDM2/p53/Bcl2/Bax pathways," Cell Death Discovery, vol. 5, no. 1, article 89, 2019.

[24] R. Aguirre-Gamboa, H. Gomez-Rueda, E. Martínez-Ledesma et al., "SurvExpress: an online biomarker validation tool and database for cancer gene expression data using survival analysis," PLoS One, vol. 8, no. 9, article e74250, 2013.

[25] J. Dai, Y. Lu, J. Wang et al., "A four-gene signature predicts survival in clear-cell renal-cell carcinoma," Oncotarget, vol. 7, no. 50, pp. 82712-82726, 2016.

[26] A. Ziegler, S. Lange, and R. Bender, "Survival analysis: log rank test," Dtsch Med Wochenschr, vol. 132, pp. e39-e41, 2007.

[27] M. Shahid, K. M. Cho, M. N. Nguyen et al., "Prognostic value and their clinical implication of 89-gene signature in glioma," Oncotarget, vol. 7, no. 32, pp. 51237-51250, 2016.

[28] N. A. Obuchowski and J. A. Bullen, "Receiver operating characteristic (ROC) curves: review of methods with applications in diagnostic medicine," Physics in Medicine \& Biology, vol. 63, no. 7, article 07TR01, 2018.

[29] A. I. Bandos, B. Guo, and D. Gur, "Estimating the area under ROC curve when the fitted binormal curves demonstrate improper shape," Academic Radiology, vol. 24, no. 2, pp. 209-219, 2017.

[30] R. L. Siegel, K. D. Miller, and A. Jemal, "Cancer statistics, 2018," CA: a Cancer Journal for Clinicians, vol. 68, no. 1, pp. 7-30, 2018.

[31] S. C. Melkonian, C. R. Daniel, Y. Ye et al., "Gene-environment interaction of genome-wide association study-identified susceptibility loci and meat-cooking mutagens in the etiology of renal cell carcinoma," Cancer, vol. 122, no. 1, pp. 108-115, 2016.

[32] I. A. Deckers, P. A. van den Brandt, M. van Engeland et al., "Potential role of gene-environment interactions in ion transport mechanisms in the etiology of renal cell cancer," Scientific Reports, vol. 6, no. 1, article 34262, 2016.

[33] F. Wang and Y. Xu, "Body mass index and risk of renal cell cancer: a dose-response meta-analysis of published cohort studies," International Journal of Cancer, vol. 135, no. 7, pp. 1673-1686, 2014.

[34] H. Moch, A. L. Cubilla, P. A. Humphrey, V. E. Reuter, and T. M. Ulbright, "The 2016 WHO classification of tumours of the urinary system and male genital organs-part a: renal, penile, and testicular tumours," European Urology, vol. 70, no. 1, pp. 93-105, 2016.

[35] J. C. Cheville, C. M. Lohse, H. Zincke, A. L. Weaver, and M. L. Blute, "Comparisons of outcome and prognostic features among histologic subtypes of renal cell carcinoma," The American Journal of Surgical Pathology, vol. 27, no. 5, pp. 612-624, 2003.

[36] M. Itsumi and K. Tatsugami, "Immunotherapy for renal cell carcinoma," Clinical and Developmental Immunology, vol. 2010, Article ID 284581, 8 pages, 2010.

[37] X. Yu, B. Wang, X. Li et al., "The significance of metastasectomy in patients with metastatic renal cell carcinoma in the era of targeted therapy," BioMed Research International, vol. 2015, Article ID 176373, 8 pages, 2015.

[38] H. Abe and T. Kamai, "Recent advances in the treatment of metastatic renal cell carcinoma," International Journal of Urology, vol. 20, no. 10, pp. 944-955, 2013. 